\title{
Uplift Capacity of Shallow Anchors Based on the Generalized Nonlinear Failure Criterion
}

\author{
Zou Jin-feng and Xia Ming-yao \\ School of Civil Engineering, Central South University, No. 22, Shaoshan South Road, \\ Central South University Railway Campus, Changsha, Hunan 410075, China
}

Correspondence should be addressed to Zou Jin-feng; zoujinfeng_csu@163.com

Received 23 November 2015; Revised 28 February 2016; Accepted 13 March 2016

Academic Editor: Stefan Balint

Copyright (C) 2016 Z. Jin-feng and X. Ming-yao. This is an open access article distributed under the Creative Commons Attribution License, which permits unrestricted use, distribution, and reproduction in any medium, provided the original work is properly cited.

\begin{abstract}
The shape of rapture surface for shallow anchors was presented and the effects of parameters on the shape of rapture surface were analyzed. Based on the generalized nonlinear failure criterion and the limit equilibrium principle, an approach, which takes into account the shape of rapture surface, dip angle of shallow anchors, and varieties of rock and soil mass, is proposed. The effects of different parameters on ultimate uplift force of shallow anchors are discussed. In order to validate the practicability of the proposed formula, a comparison between the theoretical solutions and local test results is conducted. The agreement shows that the proposed formula is effective. The results of the proposed approach show that the ultimate uplift capacity of shallow anchor increases nonlinearly with the shape coefficient linearly increasing. The values of ultimate uplift force local test are in the range of the results of the proposed method with shape coefficient from 0 to 1.
\end{abstract}

\section{Introduction}

The design of shallow anchors is still empirical so far, especially the ultimate pullout capacity. A common method to verify partly the shallow anchor design is the pullout test but it is difficult and expensive; and the working conditions of the rock and soil mass around the shallow anchor are always unknowable. As the range of applications for shallow anchor expands, a greater understanding of their behaviors including the ultimate pullout capacity is required. In order to improve the shallow anchor design, it is necessary to have a good understanding about the calculation of the ultimate pullout capacity in the shallow anchor, especially for the important engineering applications. The ultimate pullout capacity of shallow anchor in rock and soil mass is helpful for the design because the ultimate pullout capacity provides the essential information related to the working status of the shallow anchor, which is a reasonable basis for the adjustment of the design.

Analysis of the ultimate pullout force of shallow anchors in rock and soil mass is required in a wide variation of geotechnical, petroleum, and mining engineering problems such as in the design of boreholes and mine shafts. Reviews of those contributions may be found in published journal [17]. In most of the past analyses reported, the rock and soil mass was conventionally assumed to be governed by a linear Mohr-Coulomb yield criterion. However, the experimental results show that the intermediate principal stress is the important characteristic of rock and soil mass. In many practical situations, for instance in a jointed rock mass and crash rock mass, such yield criteria may not be justified and a nonlinear yield criterion such as generalized nonlinear failure criterion would be more appropriate [8-13]. On the other hand, the interaction mechanism between the shallow anchors and the rock and soil mass is not well understood. The shallow anchor has been commonly determined based on local observations and on empirical approaches. In order to estimate the capacity and displacement of shallow anchor, most of reports presented by some scholars are based on the Mohr-Coulomb failure criterion and linear geometric failure surface in sand. For instance, Vanitha et al. proposed an analytical model to predict the net uplift capacity of pile group anchors with limit equilibrium method and truncated cone model based on the experiment investigations [6]. Hanna et al. presented an analytical model to predict the pullout capacity and the load-displacement relationship for 
shallow single vertical helical and plate anchors, with the assumption that failure mechanism consisted of logarithmic spiral rupture in sand [14]. Based on the failure surface of straight line originating from the edge of the strip anchor at an angle, Deshmukh et al. [15] proposed a theoretical analysis of net uplift capacity of horizontal strip anchor in cohesionless soil using Koiter's equation. At the same time, he presented another model for the pile anchors with the failure surface of cone frustum in cohesionless soil. Choudhury and Subba Rao [16] proposed a semianalytical method for the net uplift capacity with the log-spiral failure surface and pseudostatic seismic forces. At the same time, various research methods have been used to study the bearing behavior of anchor, especially for the displacement and deformation of anchor. For example, Farmer [17] presented the engineering character of anchors instrumented in concrete, limestone, and chalk by using the theoretical and numerical methods and local test. Cai et al. [5] proposed a method for anchors to analyze the interaction behavior of the rock bolt and the surrounding rock mass based on an improved Shear-Lag Model. Abramento and Whittle [18] presented a new analysis method to predict the tensile stress distribution and loadelongation response for identifying four successive phases in the pullout response performed on thin, extensible, and planar soil reinforcements. Serrano and Olalla [19] proposed a method for the tensile resistance of rock anchors with the published rupture surface shape based on the Hoek-Brown failure criterion.

Besides those, although researches of failure surface shape have been presented by most published papers, the failure surface shape for shallow anchor is effective with certain conditions [20-22]. For instance, Mariupol'skii [23] proposed a method for calculating the ultimate capacity of anchor foundations based on the rapture surface deduced from test results. Deshmukh et al. [15] presented an analysis method for net uplift capacity of horizontal strip anchor in cohesionless soil with the Kotter's equation based on the assumption that a plane failure surface inclined at a characteristic angle with the ground surface. Based on the failure rapture of laboratory test for shallow single vertical helical and plate anchors in sand, Hanna et al. [14] presented a model to predict the pullout capacity and the load-displacement relationship with the limit equilibrium technique.

In order to overcome the above defections, an analytical model based on an introduced model for shallow anchor is developed. The presented model is based on the proposed shape of failure rapture. A back analysis method was proposed to calculate the ultimate pullout capacity and the effect of parameters on the ultimate pullout capacity. The analysis of parameters for rapture surface shape and ultimate pullout capacity was conducted.

\section{Analysis of Failure Mechanism for Uplift Piles}

The failure surface shape and the failure mechanism in different rock and soil mass have been studied by many researchers and most of assumptions for rupture surface shape of shallow anchor subjected to limit load were presented. Published data and test results have been summarized and studied by Zou et al. [24]. A new rapture surface shape for shallow anchor subjected to a vertical force is developed considering the following boundary condition: at the surface failure outlet, the angle between the failure surface and the ground surface is $\pi / 4-\varphi / 2$; and a parameter equation of failure surface shape for shallow anchor has been proposed as shown in Figure 1.

The parameter equation of failure surface shape for shallow anchor can be expressed as

$$
x=r_{0}+\frac{L}{(n+1) \tan (\pi / 4-\varphi / 2)}\left(\frac{z}{L}\right)^{(n+1)} \text {, }
$$

where $r_{0}$ is the radius of shallow anchor, $\varphi$ is the friction angle of rock and soil mass, $L$ is the length of shallow anchor, and $n$ is parameters of failure surface shape.

As $n \rightarrow \infty, n \rightarrow 0$, and $0<n<1$, the failure surface in (1) is $a, b$, and $c$ in Figure 1, respectively.

The effect of parameters on failure surface shaped is shown in Figures 2-7 corresponding to $r_{0}=0.055 \mathrm{~m}, L=$ $12 \mathrm{~m}, \varphi=45^{\circ}$, and $n=0$.

It can be seen from Figures 2-7 that (1) the failure surface shape will be narrowing with $n$ increasing and will be widening with $L$ or $z$ increasing; (2) the parameter $\varphi$ has no significant effect on failure surface shape with $n$ increasing; (3) the failure surface shape will be widening with $z$ or $\varphi$ increasing as $z>8 \mathrm{~m}$ and $\varphi>40^{\circ}$; and (4) the failure surface shape will be widening with $\varphi$ or $n$ increasing as $n<5$ and $\varphi>20^{\circ}$.

\section{Generalized Nonlinear Failure Criterion}

Although the Mohr-coulomb and Hoek-Brown failure criterion is adopted by most researchers [25-32], the intermediate principal stress is not considered. According to the literature [8], the generalized nonlinear failure criterion can be expressed as in Figure 8.

And the failure criterion is given:

$$
\tau=M_{f}\left(\frac{\sigma_{n}+\sigma_{t}}{p_{r}}\right)^{m} p_{r}
$$

where $\sigma_{t}$ is the three-dimensional extension strength and $M_{f}\left(M_{f}=q / p_{r}\right)$ is the failure stress ratio under a given reference pressure $p_{r}$. For frictional materials, the range of frictional angle is $0^{\circ}-90^{\circ}$ and the corresponding range of $M_{f}$ is $0<M_{f}<3 . m$ is the material constant reflecting the influence of mean principal stress on strength, $0<m<1$. $\sigma_{n}$ and $\tau$ are the positive and shear stress on the cut surface, respectively.

\section{Ultimate Pullout Capacity}

Taking the shallow anchor as an example, the analysis model of shallow anchor subjected to pullout load is shown in Figure 9. The rock and soil mass is assumed to be homogeneous and isotropic and behaves as an elastic-plastic material and obeys the generalized nonlinear failure criterion. 


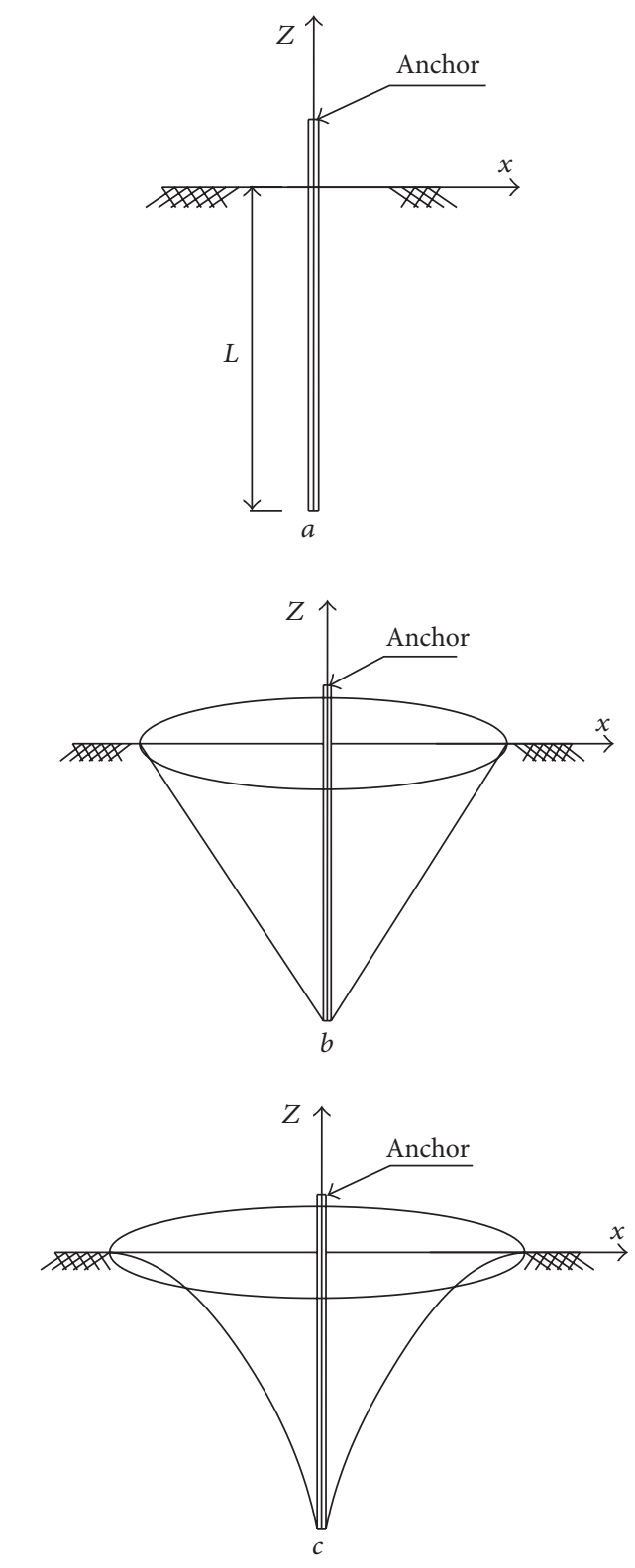

Figure 1: Typical rupture surface of shallow anchors.

The balance equilibrium of the infinitesimal element is scratched in Figure 9 in terms of the balance of the infinitesimal element for the anchor, the surrounding rock and soil mass, and the matrix together with the reinforcement in the Cartesian coordinate system, respectively; the equilibrium equation of vertical forces of the infinitesimal section in the failure region is expressed as follows based on the theory of limit equilibrium and the equation for rupture surface shape:

$$
d P=2 \pi q d x+\pi \gamma^{\prime} x^{2} d z+2 \pi\left[\tau \sin \theta+\sigma_{n} \cos \theta\right] x d z,
$$

where $\gamma$ is the soil unit weight, $d z$ is the depth of infinitesimal element, $d P / d z$ is the increment of vertical antipull load for the infinitesimal element, $q$ is the uniformly distributed load on the infinitesimal element, $x$ is the radius at the bottom of the infinitesimal element, $d x$ is difference value of the radius

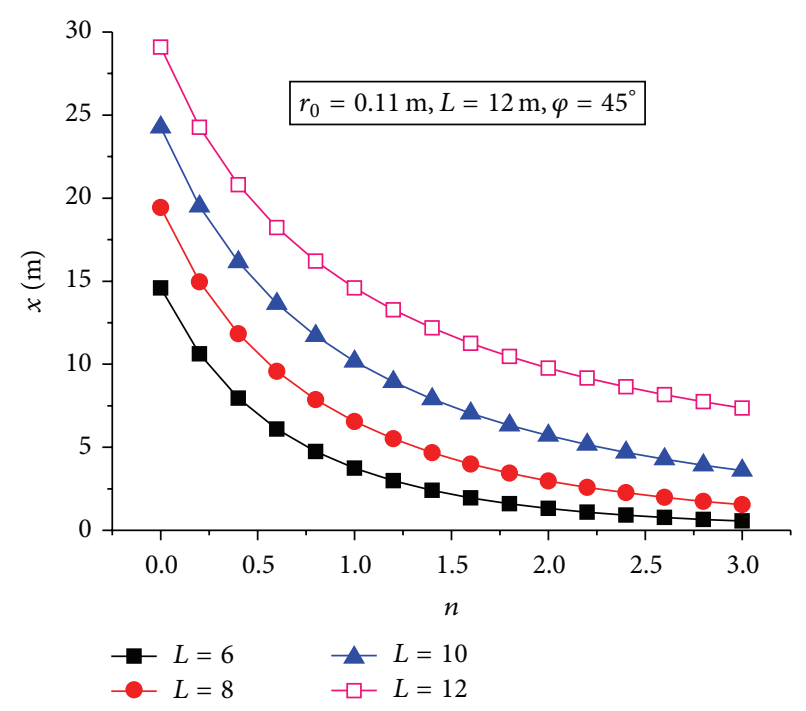

FIGURE 2: Relationships between $x$ and $n$ with different value of $L$.

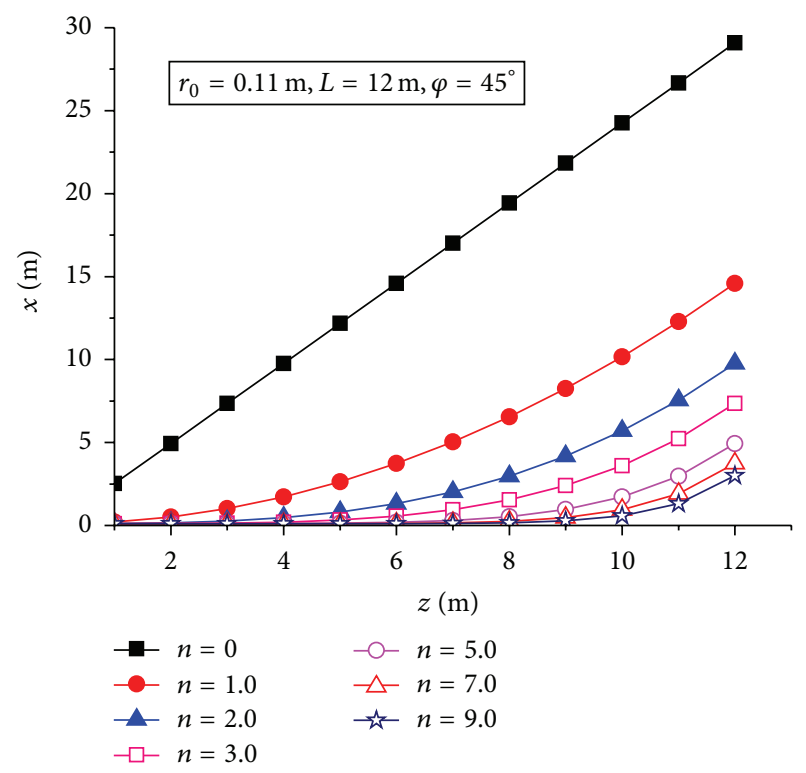

FIGURE 3: Relationships between $x$ and $z$ with different value of $n$.

between the upper and bottom surface of the infinitesimal element, $\tau$ is the tangential stress on the failure surface, and $\sigma_{n}$ is the normal stress on the failure surface, which is expressed as

$$
\sigma_{n}=\left[\gamma(L-z)+\gamma^{\prime}\left(L-z-\frac{\Delta z}{2}\right)\right]\left[\cos \theta+k_{0} \sin \theta\right]
$$

where $k_{0}$ is the lateral pressure coefficient of the soil mass and $z$ is the vertical distance from the anchor plate to the infinitesimal section. 


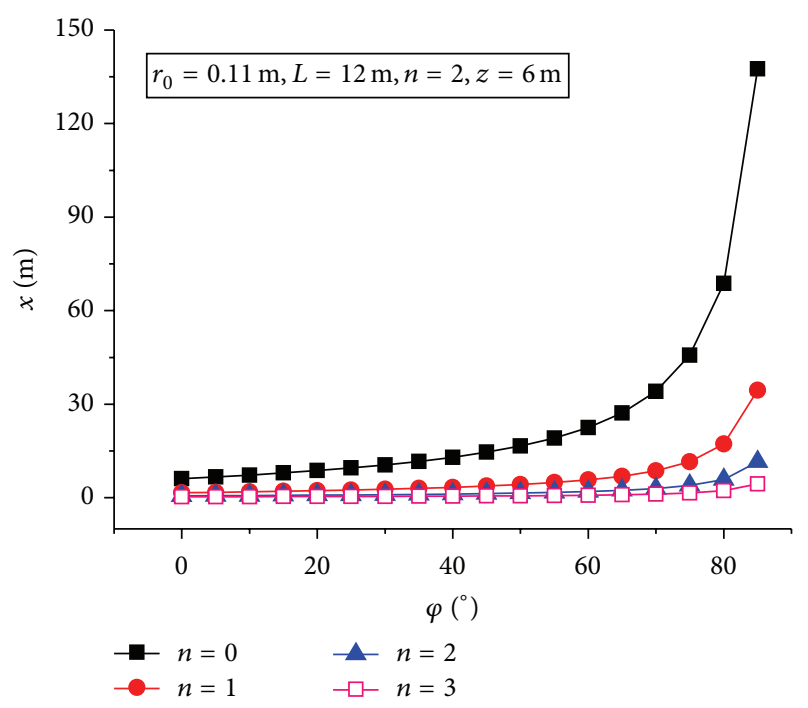

FIGURE 4: Relationships between $x$ and $\varphi$ with different value of $n$.

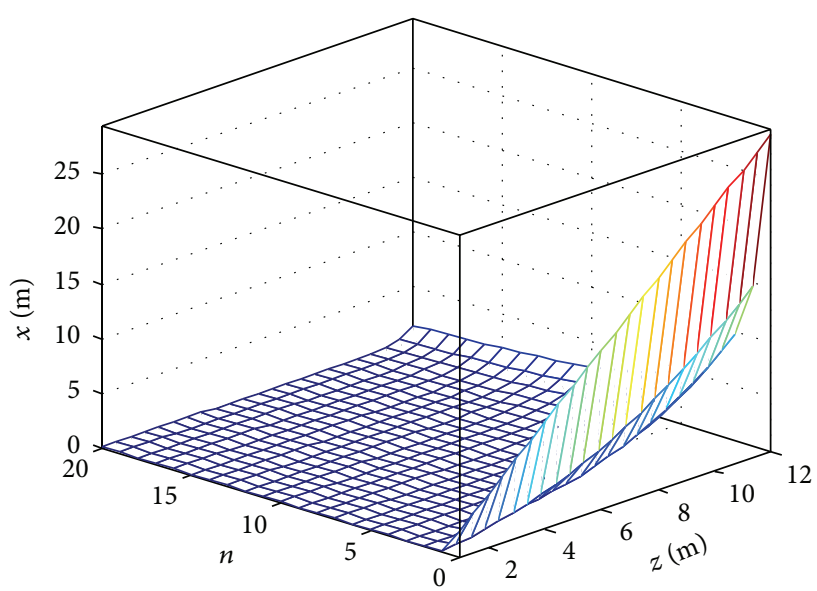

FIGURE 5: Relationships between $x$ and parameters of $n$ and $z$.

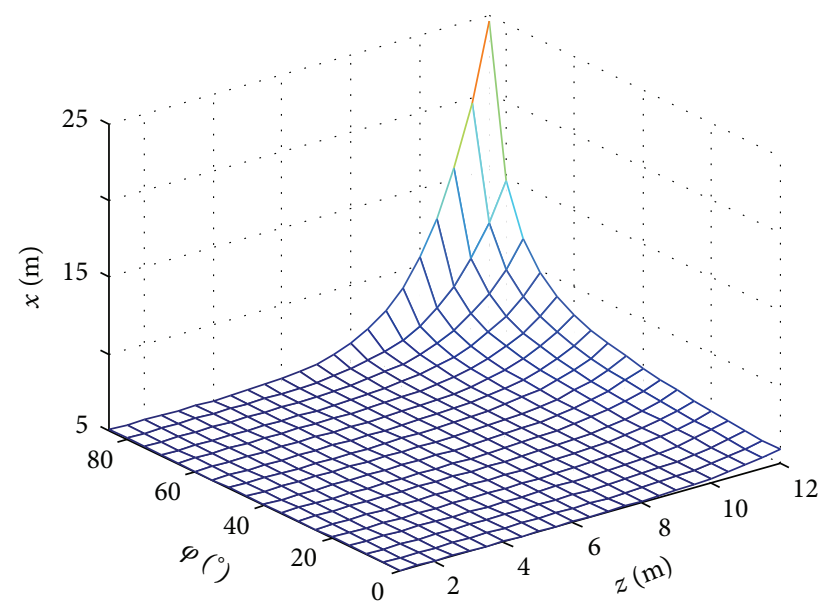

FIgURE 6: Relationships between $x$ and parameters of $\varphi$ and $z$.

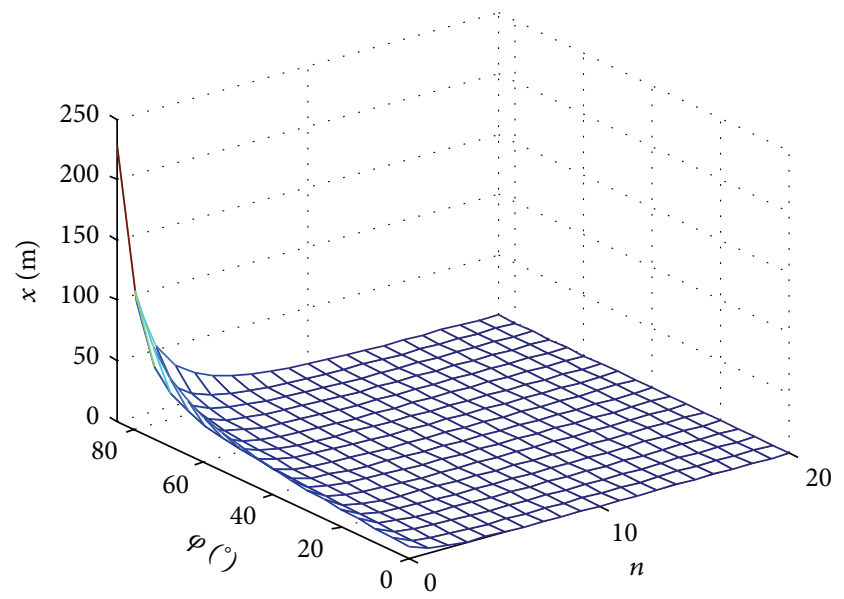

FIGURE 7: Relationships between $x$ and parameters of $\varphi$ and $n$.

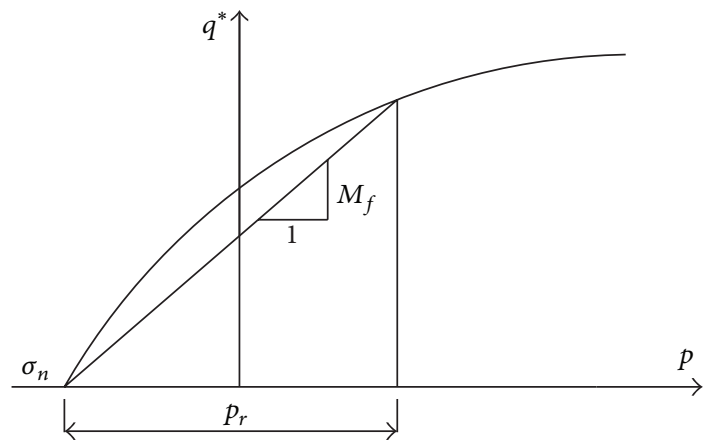

FIgURE 8: Failure curve on triaxial compression meridian plane.

According to equilibrium conditions of vertical force for infinitesimal element, $\Delta P$ can be obtained as follows:

$$
\begin{aligned}
\Delta P= & \left\{\pi q\left[(x+\Delta x)^{2}-x^{2}\right](q+\Delta q)+\pi x^{2} \Delta q\right\} \\
& +\pi\left(x+\frac{\Delta x}{2}\right)^{2} \Delta z \gamma^{\prime} \\
& +2 \pi\left(x+\frac{\Delta x}{2}\right)\left(\tau \sin \theta-\sigma_{n} \cos \theta\right) \Delta z .
\end{aligned}
$$

Ignoring the higher order terms of differentiation and taking limit equilibrium equation (3), the following expression is derived by $\Delta q=\gamma \Delta z$ :

$$
\begin{aligned}
d P= & 2 \pi q x d x+\pi x^{2} \gamma d z+\pi \gamma^{\prime} x^{2} d z \\
& +2 \pi\left[\tau \sin \theta-\sigma_{n} \cos \theta\right] x d z .
\end{aligned}
$$

According to Figure 9, $q=\gamma(L-z)$ and $d x / d z=$ $\cot (\pi / 4-\varphi / 2)$ are obtained. Substituting (2) and (4) into (6), the vertical antipull load increment at an arbitrary depth $z$ can be given by the following equation:

$$
\begin{aligned}
\frac{d P}{d z} & =2 \pi\left[\left(\gamma+\gamma^{\prime}\right)(L-z)\right] x \cot \theta+2 \pi x\{\tau \sin \theta \\
& \left.-\left[\left(\gamma+\gamma^{\prime}\right)(L-z)\right] \cdot\left[\cos \theta+k_{0} \sin \theta\right] \cos \theta\right\},
\end{aligned}
$$




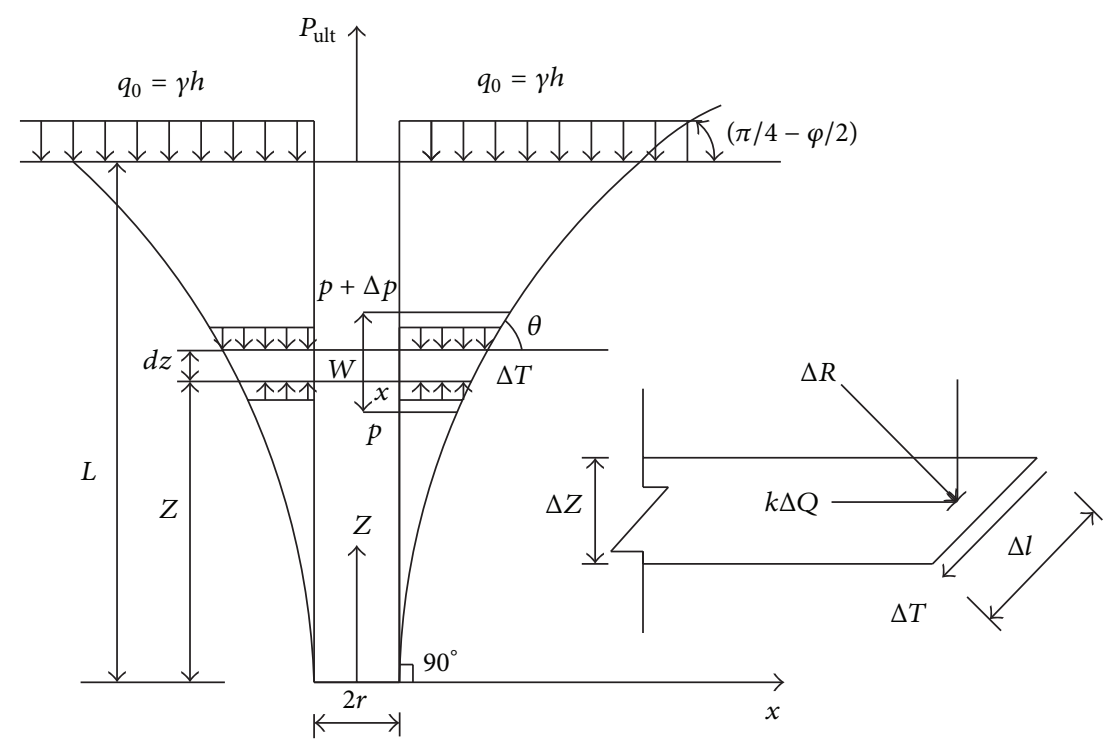

FIGURE 9: The calculation model for ultimate pullout force of piles.

where $\cos \theta=\sqrt{1 /\left(1+\tan ^{2} \theta\right)}, \sin \theta=\sqrt{\tan ^{2} \theta /\left(1+\tan ^{2} \theta\right)}$, and $\cot \theta=d x / d z=(1 / \tan \theta)(L / z)$.

The above equation may be solved by integrating from 0 to $L$, and the formulation of ultimate pullout load for shallow anchor can be expressed as

$$
\begin{aligned}
P & =\int_{0}^{L}\left(2 \pi\left[\left(\gamma+\gamma^{\prime}\right)(L-z)\right] x \cot \theta+2 \pi x\{\tau \sin \theta\right. \\
& -\left[\left(\gamma+\gamma^{\prime}\right)(L-z)\right] \\
& \left.\left.\cdot\left[\cos \theta+k_{0} \sin \theta\right] \cos \theta\right\}\right) d z .
\end{aligned}
$$

As $\theta=90^{\circ}$, the shallow anchor will be destroyed along the contact surface between the slurry wall and the hole; its fracture surface will be the type $a$ as shown in Figure 1. According to (8), the ultimate pullout load of shallow anchor can be given as

$$
P_{\text {ult }}=\pi D L \tau^{*}=\pi D L \cdot M_{f}\left(\frac{\sigma_{n}+\sigma_{t}}{p_{r}}\right)^{m} p_{r},
$$

where $P_{\text {ult }}$ is the ultimate pullout load, $\sigma_{n}$ is the maximum between rock and soil pressure and the grouting pressure for calculation, and $D$ is the anchor diameter.

The effects of parameters on the characteristic of ultimate pullout load are shown in Figures 10-17 with respect to $r_{0}=$ $0.055 \mathrm{~m}, m=1.6, n=0, h=6.0 \mathrm{~m}, k=0.75, M=1.07$, $\sigma_{n}=500 \mathrm{kPa}, M_{f}=1.12, P_{r}=100 \mathrm{kPa}$, and $\sigma_{t}=0 \mathrm{kPa}$.

It can be seen from Figure 10 that ultimate pullout load will increase nonlinearly with $m$ increasing and will increase with $L$ increasing.

Figure 11 shows that ultimate pullout load will decrease nonlinearly with $m$ increasing as $m>1$, will be a constant as $m=1$, and will increase linearly as $m=0$.

It is shown from Figure 12 that ultimate pullout load will be increased nonlinearly with $z$ increasing and will be increased with $m$ increasing.

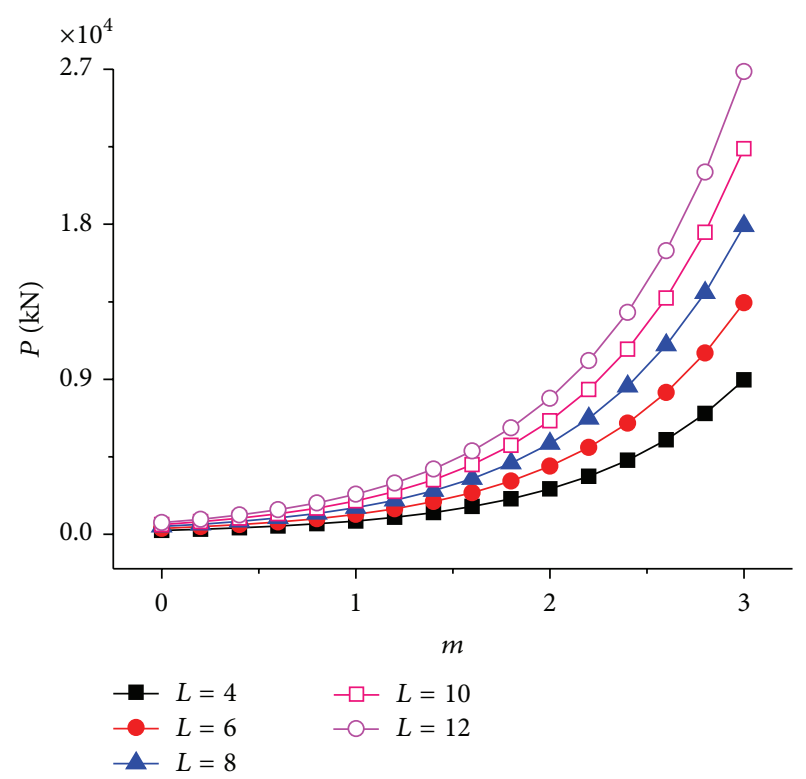

FIgURE 10: Relationships between $P$ and $m$ with different value of $L$.

It can be found from Figure 13 that ultimate pullout load will increase nonlinearly with $z$ increasing and will be increasing with $n$ increasing.

It is revealed from Figure 14 that the ultimate pullout will increase with $L$ increasing, will decrease as $\theta<15^{\circ}$, and then will increase as $\theta>15^{\circ}$.

It can be found from Figure 15 that the ultimate pullout will increase with $L$ or $n$ increasing, especially for $n<1$ and $L>6 \mathrm{~m}$.

Figure 16 shows that the ultimate pullout load will increase nonlinearly with $m$ increasing, and there is no significant effect of $n$ on the ultimate pullout load. 
TABLE 1: Comparison of the local test and proposed method results.

\begin{tabular}{|c|c|c|c|c|c|c|c|c|c|c|c|c|c|}
\hline \multirow{3}{*}{ Category } & \multicolumn{12}{|c|}{ Results of proposed method (kPa) } & \multirow{3}{*}{ Results of local test $(\mathrm{kPa})$} \\
\hline & & & & & & & $n$ & & & & & & \\
\hline & & 0 & 0.1 & 0.2 & 0.3 & 0.4 & 0.5 & 0.6 & 0.7 & 0.8 & 0.9 & 1 & \\
\hline \multirow{2}{*}{ Clay } & 1 & 731.34 & 616.12 & 525.40 & 452.81 & 393.91 & 345.54 & 305.39 & 271.74 & 243.30 & 219.09 & 198.33 & 332.5 \\
\hline & 2 & 710.83 & 598.87 & 510.73 & 440.19 & 382.96 & 335.95 & 296.94 & 264.24 & 236.61 & 213.08 & 192.91 & 341.7 \\
\hline \multirow{2}{*}{ Sandy soil } & 1 & 1111.88 & 952.43 & 825.04 & 721.62 & 636.51 & 565.63 & 505.99 & 455.35 & 411.98 & 374.59 & 342.12 & 400.5 \\
\hline & 2 & 1133.16 & 970.72 & 840.95 & 735.59 & 648.88 & 576.67 & 515.90 & 464.30 & 420.12 & 382.01 & 348.93 & 411.3 \\
\hline \multirow{2}{*}{$\begin{array}{l}\text { Coarse-grained } \\
\text { soil }\end{array}$} & 1 & 670.81 & 566.96 & 484.92 & 419.06 & 365.43 & 321.25 & 284.46 & 253.53 & 227.31 & 204.92 & 185.66 & 194.6 \\
\hline & 2 & 600.89 & 507.90 & 434.43 & 375.45 & 327.43 & 287.87 & 254.92 & 227.23 & 203.75 & 183.70 & 166.46 & 188.2 \\
\hline
\end{tabular}

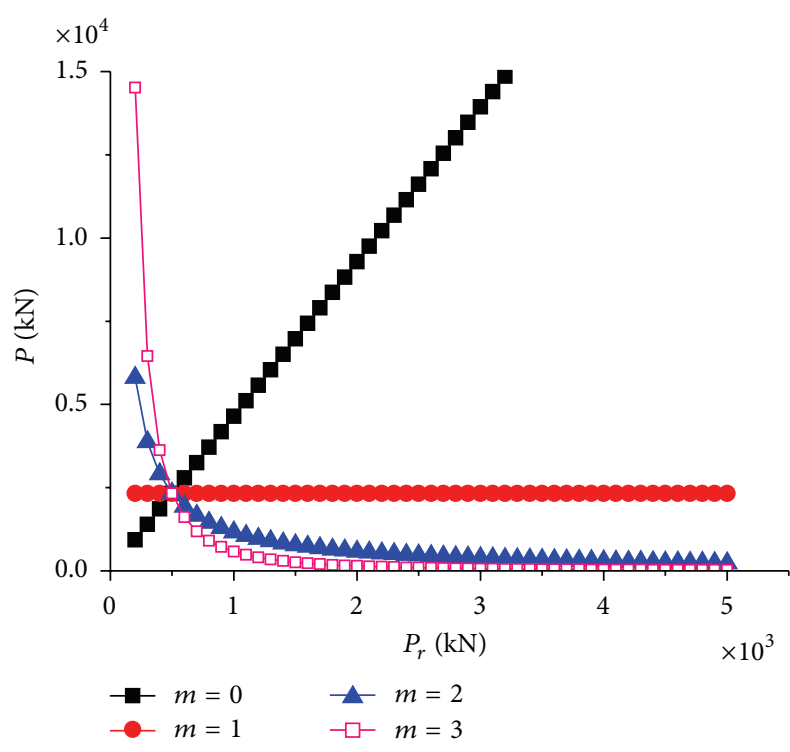

FIGURE 11: Relationships between $P$ and $P_{r}$ with different value of $m$.

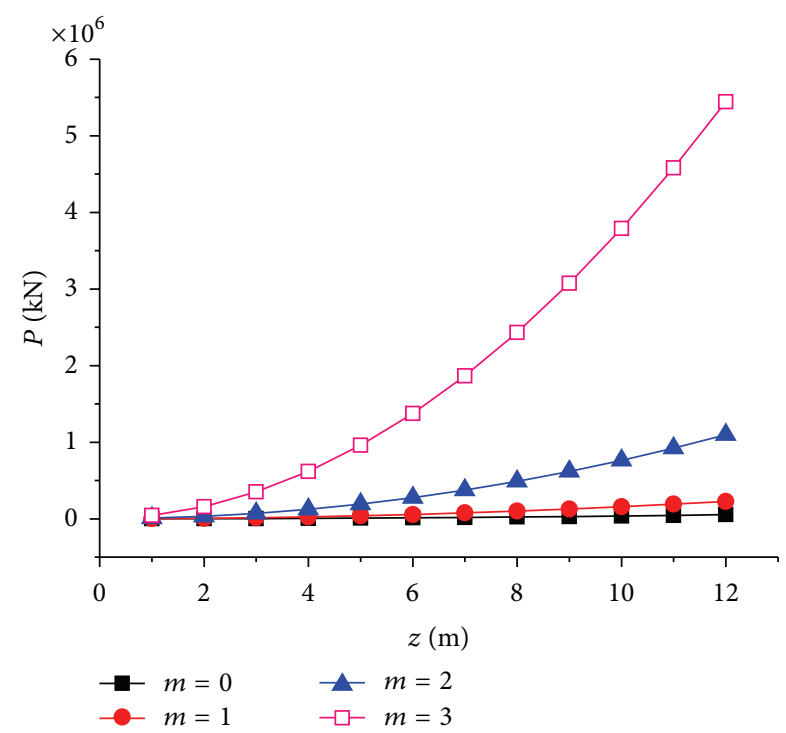

FIgURE 12: Relationships between $P$ and $z$ with different value of $m$.

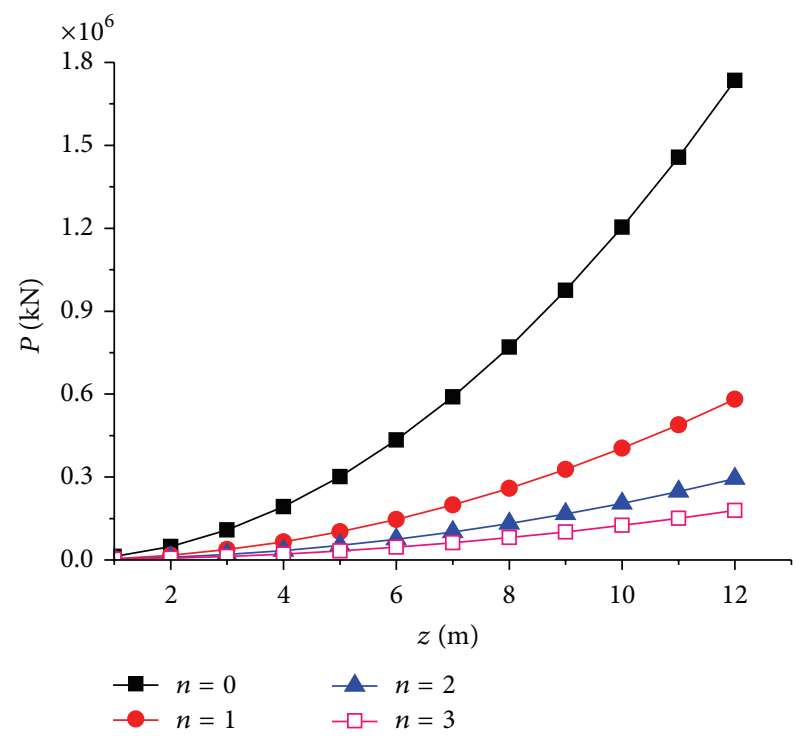

FIGURE 13: Relationships between $P$ and $z$ with different value of $n$.

It can be seen from Figure 17 that the ultimate pullout load will increase with $L$ and $m$ increasing as $m>1.4$.

Generally speaking, there is a significant effect of $L, m, z, \varphi$, and $P_{r}$ on ultimate pullout load from Figures 1017.

\section{Comparison of Theoretical and Local Test Results}

In order to validate the reliability of the proposed method, a model and a pier uplift pile test data were taken as examples for comparison. The results of the proposed method and local test are shown in Table 1 corresponding to (1) $L=3.15 \mathrm{~m}, D=$ $0.0508 \mathrm{~m}, \varphi=28^{\circ}, \gamma=16.8 \mathrm{kN} / \mathrm{m}^{3}, M_{f}=1.12, p_{r}=147 \mathrm{kPa}$, $m=1$, and $\sigma_{t}=0$; the experiment results of ultimate capacity are $332.5 \mathrm{kN}$ and $341.7 \mathrm{kN}$. (2) $L=2.51 \mathrm{~m}, D=0.041 \mathrm{~m}$, $\varphi=36^{\circ}, \gamma=25 \mathrm{kN} / \mathrm{m}^{3}, M_{f}=1.68, p_{r}=100 \mathrm{kPa}, m=0.62$, and $\sigma_{t}=0$; the experiment results of ultimate capacity are $400.5 \mathrm{kN}$ and $411.3 \mathrm{kN}$. (3) $L=2.1 \mathrm{~m}, D=0.0308 \mathrm{~m}, \varphi=32^{\circ}$, $\gamma=24.6 \mathrm{kN} / \mathrm{m}^{3}, M_{f}=1.86, p_{r}=100 \mathrm{kPa}, m=0.9$, and 


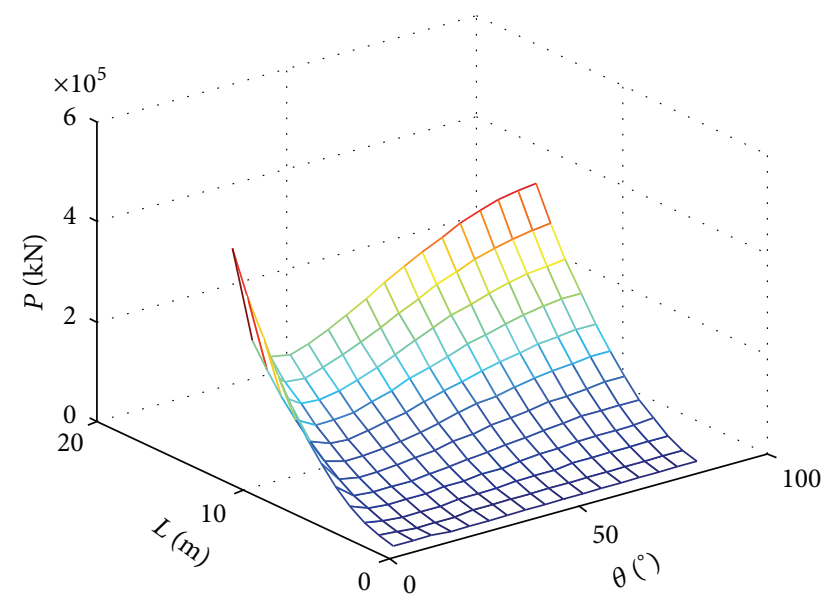

FIgURE 14: Relationships between $P$ and parameters of $\theta$ and $L$.

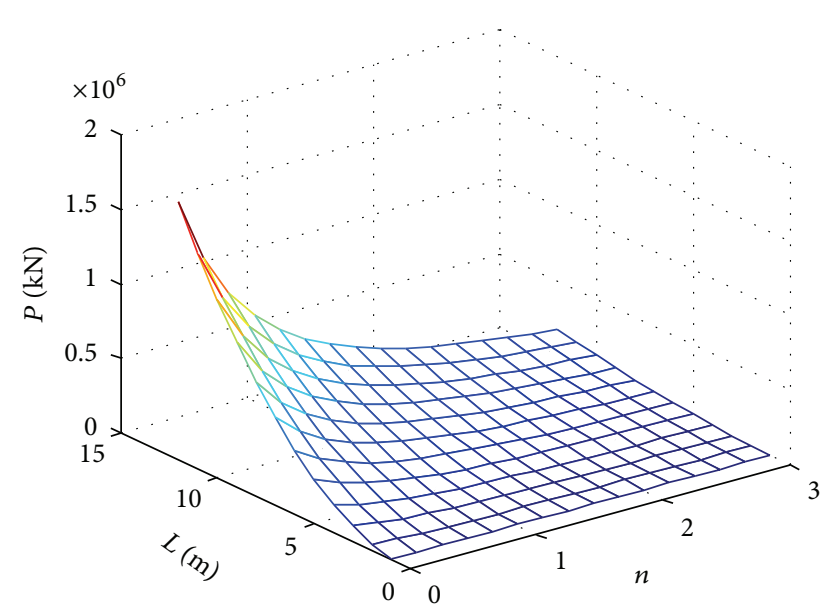

Figure 15: Relationships between $P$ and parameters of $L$ and $n$.

$\sigma_{t}=0$; the experiment results of ultimate capacity are $194.6 \mathrm{kN}$ and $188.2 \mathrm{kN}$.

It can be seen from Table 1 that the ultimate pullout capacity increases nonlinearly with parameter $n$ increasing. The surface shape cannot be determined because of disturbance when rock and soil mass is excavated. So, the parameter $n$ cannot be accurately determined and the values of ultimate uplift force are calculated with $n$ from 0 to 1 . It is shown from Table 1 that the results of local test are all in the range of the results of the proposed method.

The comparison proves the theoretic reliability and validity in this work, so it can provide consultancy for shallow anchor design. The differences between the theoretical calculation and the local test data come from other factors such as the anchor length, the anchor diameter, and the strength of the soil around the anchor. The effects of these factors on the displacement and deformation of uplift piles demand more study.

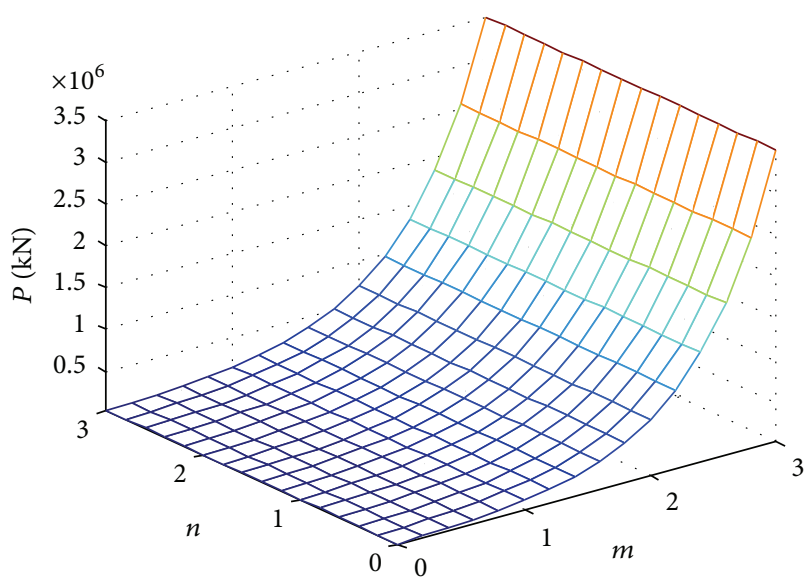

Figure 16: Relationships between $P$ and parameters of $n$ and $m$.

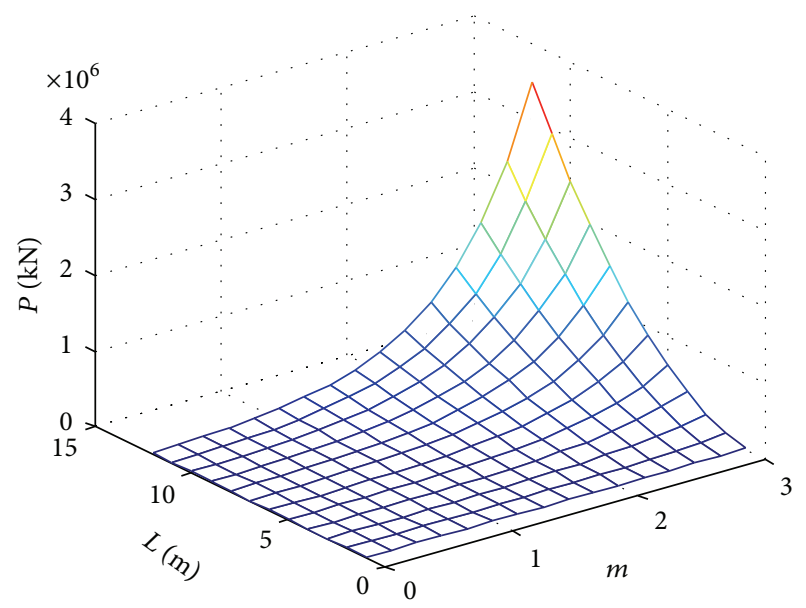

Figure 17: Relationships between $P$ and parameters of $L$ and $m$.

\section{Conclusions}

(1) A new rapture surface shape is described in the present analysis. Based on the rapture surface equation and the limit equilibrium principle, rational calculation method for calculating the ultimate uplift capacity of the shallow anchor embedded in rock and soil mass is formulated.

(2) The results of theoretical solutions and local tests show that the present method can provide a certain reasonable reference for designing of uplift capacity of shallow anchor.

\section{Notations}

c: Cohesion of rock and soil mass $\left[\mathrm{FL}^{-2}\right]$

$D$ : The anchor diameter [L]

$k_{0}$ : The lateral pressure coefficient of the soil mass [-]

$L$ : The length of shallow anchor [L]

$m$ : Material constant reflecting the influence of mean principal stress on strength $[-]$ 
$M_{f}$ : The failure stress ratio under a given reference pressure $p_{r}[-]$

$n$ : $\quad$ Parameters of failure surface shape $[-]$

$P_{r}:$ Internal pressure in the anchor hole $\left[\mathrm{FL}^{-2}\right]$

$P_{\text {ult }}$ : Ultimate pullout load $\left[\mathrm{FL}^{-2}\right]$

$q$ : The uniformly distributed load on the infinitesimal element $\left[\mathrm{FL}^{-2}\right]$

$r_{0}$ : Radius of shallow anchor [L]

$x$ : The radius at the bottom of the infinitesimal element [L]

$z$ : The vertical distance from the anchor plate to the infinitesimal section [L]

$\tau$ : The tangential stress on the failure surface $\left[\mathrm{FL}^{-2}\right]$

$\varphi$ : $\quad$ Friction angle of rock and soil mass [-]

$\gamma:$ Soil unit weight $\left[\mathrm{FM}^{-1}\right]$

$\theta$ : The angle between the failure surface and horizon [-]

$\sigma_{n}$ : Normal stress on the failure surface $\left[\mathrm{FL}^{-2}\right]$

$\sigma_{t}$ : Three-dimensional extension strength $\left[\mathrm{FL}^{-2}\right]$.

\section{Competing Interests}

The authors declare that they have no competing interests.

\section{Acknowledgments}

This work was supported by the National Basic Research Program of China (“973” Project) (Grant no. 2013CB036004) and the National Natural Science Foundation of China (Grant no. 51208523).

\section{References}

[1] J. Kumar and K. M. Kouzer, "Vertical uplift capacity of horizontal anchors using upper bound limit analysis and finite elements," Canadian Geotechnical Journal, vol. 45, no. 5, pp. 698-704, 2008.

[2] C. Li and B. Stillborg, "Analytical models for rock bolts," International Journal of Rock Mechanics and Mining Sciences, vol. 36, no. 8, pp. 1013-1029, 1999.

[3] R. S. Merifield and S. W. Sloan, "The ultimate pullout capacity of anchors in frictional soils," Canadian Geotechnical Journal, vol. 43, no. 8, pp. 852-868, 2006.

[4] C. P. Thorne, "Uplift capacity of rapidly loaded strip anchors in uniform strength clay," Géotechnique, vol. 54, no. 8, pp. 507-517, 2004.

[5] Y. Cai, T. Esaki, and Y. J. Jiang, "An analytical model to predict axial load in grouted rock bolt for soft rock tunnelling," Tunnelling and Underground Space Technology, vol. 19, no. 6, pp. 607-618, 2004.

[6] L. Vanitha, N. R. Patra, and S. Chandra, "Uplift capacity of pile group anchors," Geotechnical and Geological Engineering, vol. 25, no. 3, pp. 339-347, 2007.

[7] X. L. Yang and Z. X. Long, "Seismic and static 3D stability of two-stage rock slope based on Hoek-Brown failure criterion," Canadian Geotechnical Journal, vol. 53, no. 3, pp. 551-558, 2016.
[8] Y. P. Yao, D. C. Lu, A. N. Zhou, and B. Zou, "Generalized nonlinear strength theory and transformed stress space," Science in China E: Technological Sciences, vol. 47, no. 6, pp. 691-709, 2004.

[9] L. Zhao, F. Yang, Y. Zhang, H. Dan, and W. Liu, "Effects of shear strength reduction strategies on safety factor of homogeneous slope based on a general nonlinear failure criterion," Computers and Geotechnics, vol. 63, pp. 215-228, 2015.

[10] J.-F. Zou and S.-S. Li, “Theoretical solution for displacement and stress in strain-softening surrounding rock under hydraulicmechanical coupling," Science China Technological Sciences, vol. 58, no. 8, pp. 1401-1413, 2015.

[11] Z. Jin-Feng and S. Yu, "Theoretical solutions of a circular tunnel with the influence of the out-of-plane stress based on the generalized Hoek-Brown failure criterion," International Journal of Geomechanics, 2015.

[12] J.-F. Zou and Z. He, "Numerical approach for strain-softening rock with axial stress," Proceedings of the Institution of Civil Engineers-Geotechnical Engineering, 2015.

[13] Z. Jin-feng, L. Shuai-shuai, X. Yuan et al., "Theoretical solution for a circular opening in an elastic-brittle-plastic rock mass incorporating the out-of-plane stress and seepage force," KSCE Journal of Civil Engineering, vol. 20, no. 2, pp. 687-701, 2016.

[14] A. Hanna, T. Ayadat, and M. Sabry, "Pullout resistance of single vertical shallow helical and plate anchors in sand," Geotechnical and Geological Engineering, vol. 25, no. 5, pp. 559-573, 2007.

[15] V. B. Deshmukh, D. M. Dewaikar, and D. Choudhary, "Uplift capacity of horizontal strip anchors in cohesionless soil," Geotechnical and Geological Engineering, vol. 29, no. 6, pp. 977988, 2011.

[16] D. Choudhury and K. S. Subba Rao, "Seismic uplift capacity of strip anchors in soil," Geotechnical \& Geological Engineering, vol. 22, no. 1, pp. 59-72, 2004.

[17] I. W. Farmer, "Stress distribution along a resin grouted rock anchor," International Journal of Rock Mechanics and Mining Sciences \& Geomechanics Abstracts, vol. 12, no. 11, pp. 347-351, 1975.

[18] M. Abramento and A. J. Whittle, "Analysis of pullout tests for planar reinforcements in soil," Journal of Geotechnical Engineering, vol. 121, no. 6, pp. 476-485, 1995.

[19] A. Serrano and C. Olalla, "Tensile resistance of rock anchors," International Journal of Rock Mechanics and Mining Sciences, vol. 36, no. 4, pp. 449-474, 1999.

[20] K. M. Kouzer and J. Kumar, "Vertical uplift capacity of two interfering horizontal anchors in sand using an upper bound limit analysis," Computers \& Geotechnics, vol. 36, no. 6, pp. 1084-1089, 2009.

[21] X. Li, C. Gaudin, Y. Tian, and M. J. Cassidy, "Rate effects on the uplift capacity of skirted foundations on clay," in Electromagnetic Boundary Problems, p. 473, CRC Press, 2015.

[22] S. M. Rangari, D. Choudhury, and D. M. Dewaikar, "Seismic uplift capacity of shallow horizontal strip anchor under oblique load using pseudo-dynamic approach," Soils and Foundations, vol. 53, no. 5, pp. 692-707, 2013.

[23] L. G. Mariupol'skii, “The bearing capacity of anchor foundations," Soil Mechanics and Foundation Engineering, vol. 2, no. 1, pp. 26-32, 1965.

[24] J.-F. Zou, L. Li, X.-L. Yang, and Z.-W. Deng, "Study on the ultimate pullout force of pre-stressed cable based on nonlinear Mohr-Coulomb failure criterion," Chinese Journal of Geotechnical Engineering, vol. 29, no. 1, pp. 107-111, 2007. 
[25] X.-L. Yang, L. Li, and J.-H. Yin, "Seismic and static stability analysis for rock slopes by a kinematical approach," Geotechnique, vol. 54, no. 8, pp. 543-549, 2004.

[26] X.-L. Yang and J.-H. Yin, "Slope stability analysis with nonlinear failure criterion," Journal of Engineering Mechanics, vol. 130, no. 3, pp. 267-273, 2004.

[27] X.-L. Yang and J.-H. Yin, "Upper bound solution for ultimate bearing capacity with a modified Hoek-Brown failure criterion," International Journal of Rock Mechanics and Mining Sciences, vol. 42, no. 4, pp. 550-560, 2005.

[28] X.-L. Yang, "Seismic displacement of rock slopes with nonlinear Hoek-Brown failure criterion," International Journal of Rock Mechanics and Mining Sciences, vol. 44, no. 6, pp. 948-953, 2007.

[29] X.-L. Yang, "Upper bound limit analysis of active earth pressure with different fracture surface and nonlinear yield criterion," Theoretical and Applied Fracture Mechanics, vol. 47, no. 1, pp. 46-56, 2007.

[30] X. L. Yang and F. Huang, "Three-dimensional failure mechanism of a rectangular cavity in a Hoek-Brown rock medium," International Journal of Rock Mechanics and Mining Sciences, vol. 61, pp. 189-195, 2013.

[31] X. L. Yang and R. M. Yan, "Collapse mechanism for deep tunnel subjected to seepage force in layered soils," Geomechanics and Engineering, vol. 8, no. 5, pp. 741-756, 2015.

[32] X. L. Yang, J. S. Xu, Y. X. Li, and R. M. Yan, "Collapse mechanism of tunnel roof considering joined influences of nonlinearity and non-associated flow rule," Geomechanics and Engineering, vol. 10, no. 1, pp. 21-35, 2016. 


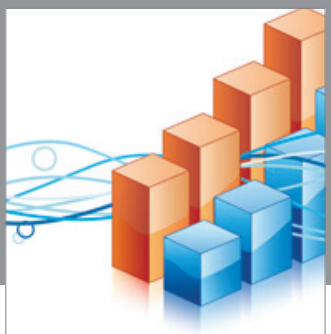

Advances in

Operations Research

vatem alat4

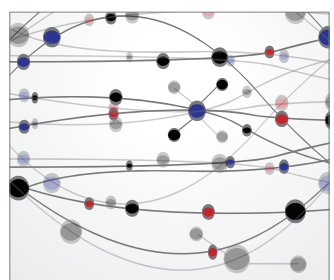

\section{The Scientific} World Journal
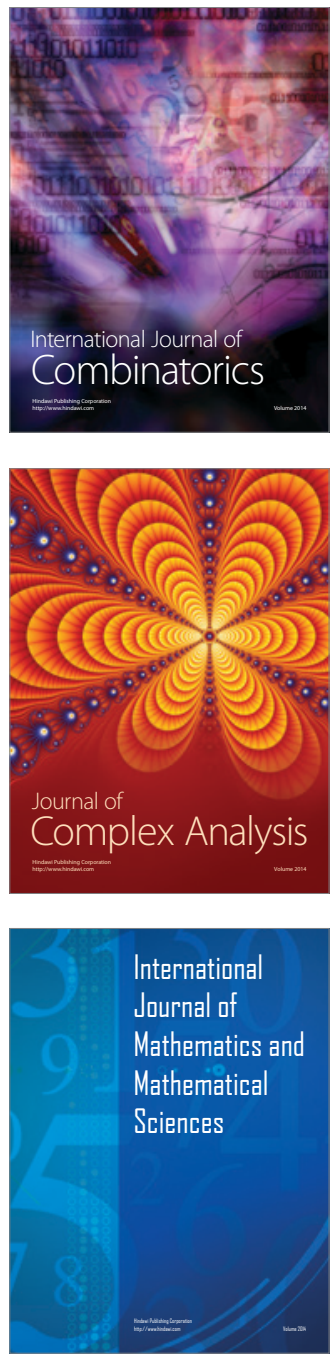
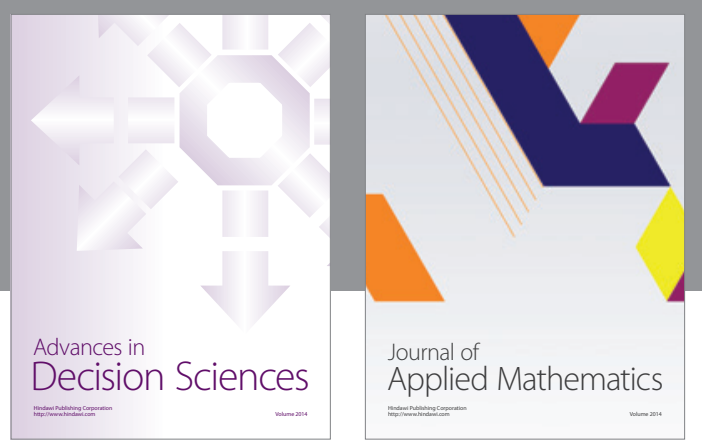

Algebra

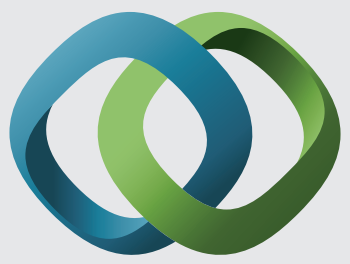

\section{Hindawi}

Submit your manuscripts at

http://www.hindawi.com
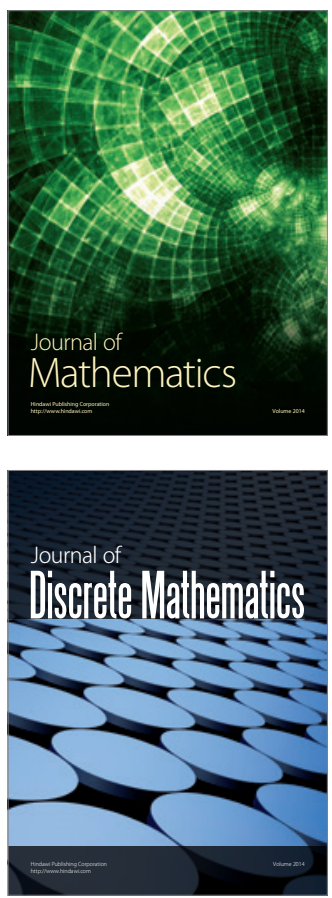

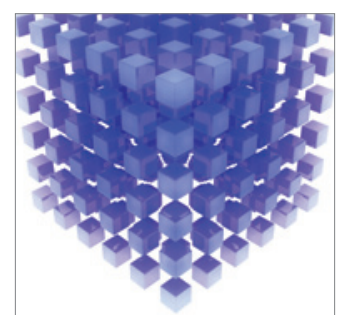

Mathematical Problems in Engineering
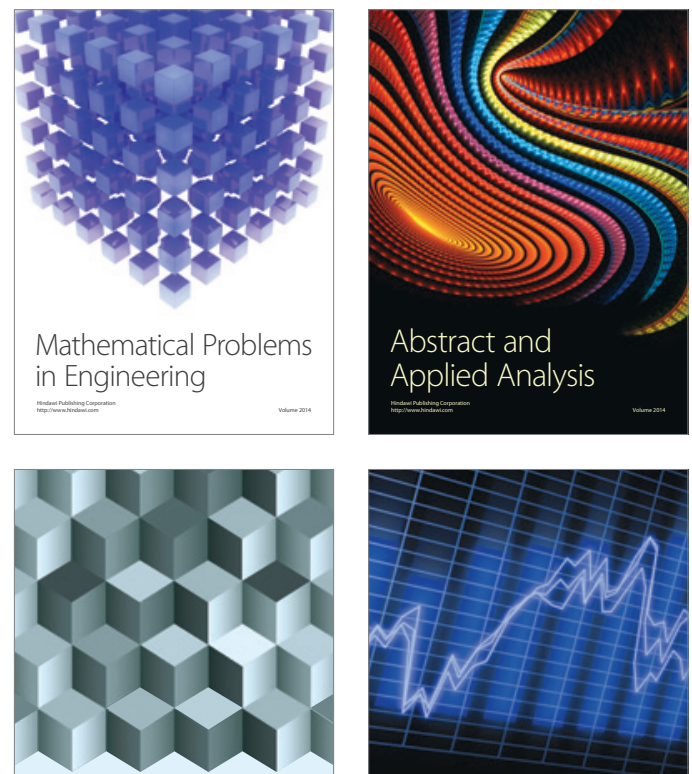

Journal of

Function Spaces

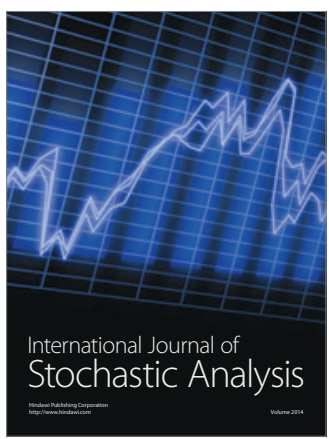

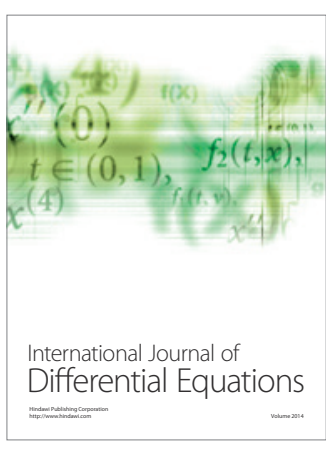
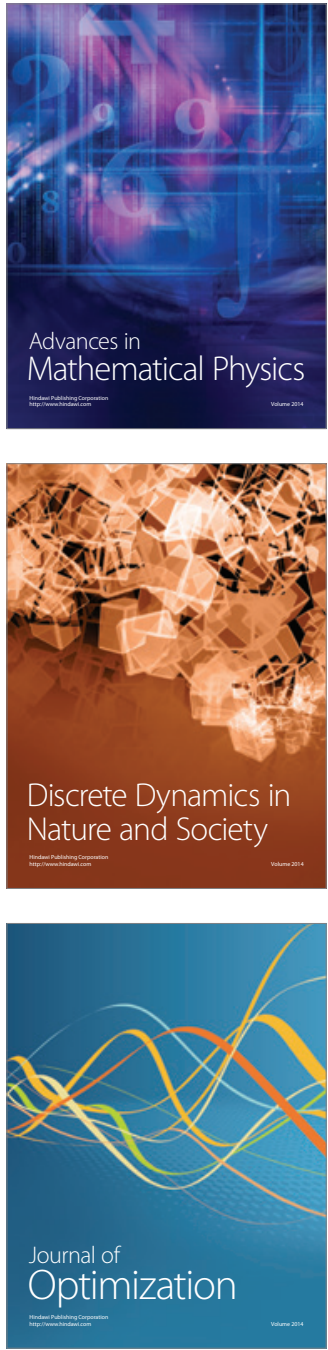